\title{
Unobtrusive Deception Detection
}

Abstract

In response to national security needs and human deception detection limitations paired with advances in sensor and computing technology research into automated deception detection has increased in recent years. These technologies rely on psychological and communication theories of deception to interpret when behavioral and physiological cues reveal deception. Despite this ever-present need, technology for detecting deception that is available to law enforcement or border guards is very limited. Based on deception theories, liars are predicted to exhibit both strategic and nonstrategic behavior. In order to develop algorithms and technology to detect and classify deception, these behaviors and physiology must be measured remotely. These measurements can be categorized by their theorized causes when lying and include arousal, negative affect, cognitive effort, behavioral control, memory, and strategic activity. One major challenge to deception detection is accounting for the variability introduced by human interviewers. Future research should focus more on behavior over the entire interaction and fusing multiple behavioral indicators of deception.

Keywords

Deception, Nonverbal behavior, Automated Deception Detection

\section{Introduction}

We could conjure a myriad of personal reasons why someone may try to deceive us. It is in the context of national security and law enforcement that failing to identify deception can have the most devastating consequences. Most officers or border guards at a congested border entry in the United States 
or European Union have less than 20 seconds to make an initial credibility assessment of passengers. This rapid credibility assessment is further confounded by their divided attention to their physical environment, monitoring of behavior, and operation of technology. Despite high confidence in their ability to detect deception, the accuracy of even these experts borders around near chance levels (Bond \& DePaulo, 2006). In response to these challenges and paired with advances in sensor and computing technology, research into automated deception detection has increased in recent years.

Deception is defined as the intentional transmission of a message intended to foster false beliefs or perceptions in the recipient (Knapp \& Comadena, 1979). This definition implies that deception is a communicative act between at least two parties (i.e., sender and receiver) and that the deceptive message can take many forms such as equivocation (omission or ambiguous messages), white lies, hedging, exaggerations, or bluffing. This implication is critical when investigating and researching affective computing applications for unobtrusively detecting deception.

Liars do not exhibit universal behavior or physiological signals in all situations. Deception is often inappropriately reduced to either simply telling the truth or lying. There are many strategies for lying, situations where lying occurs, varying consequences and power dynamics among subjects and interviewers and different interviewing styles to detect liars. All of these factors contribute to the type of behaviors and physiological responses that are exhibited and measurable for automated classification by computers.

The goal of this chapter is to provide an introduction to deception, its detection, the methods for computationally modeling its behavioral indicators, and the potential applications of deception detection technologies. The next section of this chapter introduces the existing theories that explain and predict the behaviors exhibited during deceptive and truthful people. The reader should come away from this section appreciating that deception is a complex act and the behavioral indicators are contingent on many situational and person dependent factors that must be accounted for when attempting to classify deception. 
Despite the prevalence of deception in daily life and social interactions (e.g., white lies), people are poor judges of deception. The third section highlights the importance and need for deception detection technologies to augment human decision makers and traditional tools such as the polygraph. The polygraph remains one of the only technological tools available to professional deception detectors. However, it has limited applicability (e.g., requires lengthy examination period and trained examiners) and requires the physical attachment of sensors.

The fourth section of this chapter reviews the mechanisms that cause differences in behavior between liars and truth tellers. From these mechanisms, section five reviews the corresponding behaviors, when taken in light of deception theory, are suitable for measurement and inclusion into a computational model of deceptive behavior. In addition to describing the behaviors, this section also introduces some of the recent research into their automated analysis and use for deception detection. This chapter concludes with a discussion on other potential applications for deception detection technology and future research directions.

\section{Theories of Deception}

Using computers to detect deception has great potential to improve and automate the detection of liars. There is no universal set of indicators for deception. Each deception interaction introduces its own situational contingencies that can dramatically modify the interpretation of observed behaviors. Psychological and communication theories of deception inform the interpretation of behavioral and physiological cues. These theories, summarized next, must be incorporated into the computational modeling of deceptive or truthful behavior for reliable classification.

\section{1 . Leakage Hypothesis}

In a seminal work, Ekman and Friesen (1969) hypothesized that liars would experience involuntary physiological reactions driven by increased arousal, negative affect, and discomfort that 
would "leak out" in their nonverbal behavior cues, particularly in the hands, legs, and feet. For example, nervous people may unintentionally tap their feet or touch their faces to relieve internal tensionbehaviors called adaptors that are meant to address physical or psychological discomfort.

Just as important as the observed leakage cues are the omitted ones. Liars are predicted to neglect natural gesturing and facial expressions that should accompany messages, rendering their message conveyance as unnatural. The nonverbal behaviors most susceptible to leakage are the behaviors that liars have the least control of. In western culture people have the greatest awareness and control of their facial expressions. This leaves less controllable gestures in the hands and legs as particularly diagnostic for leaked cues of deception.

\subsection{Four-Factor Theory}

The four-factor theory extended the leakage hypothesis to further explain the causes for the observed behaviors (Zuckerman, DePaulo, \& Rosenthal, 1981). The theory postulates four potential causes of leakage cues: 1) arousal, 2) negative affect 3) cognitive effort, and 4) behavioral control. For example, if the stakes or consequences are high if caught, liars may experience fear (emotion) that increases their arousal that in turn affects their behavior, such as causing an increase in vocal pitch and intensity (P. Juslin \& Scherer, 2005; Nunamaker, Derrick, Elkins, Burgoon, \& Patton, 2011).

The four-factor theory explains dissimulated nonverbal cues omitted during deceptive verbal messages, hypothesized by Ekman and Friesen (1969), as a result of over awareness and control of behavior that normally occurs naturally and automatically. Finally, the theory introduces an increased focus on the cognitive and memory influences on behavior. For unrehearsed deception, it should be more difficult to lie and maintain plausibility than when simply telling the truth. 


\subsection{Information Manipulation Theory}

Information management theory reflects the strategic element of deception in how the interaction dictates the message crafted by liars (McCornack, 1992). Specifically, liars capitalize on the tacit assumption that communication partners speak truthfully, relevantly, completely, and in an easily understood manner. For example, a liar may reduce the quantity of relevant information in their message to obfuscate the deceptive content. A liar might omit deceptive details of a story and focus disproportionately on tangential conversation topics. Within this theory, liars can be considered uncooperative speaking partners that use verbal strategies that violate conversational assumptions.

\subsection{Self-Presentational Perspective}

Long a staple in the nonverbal communication literature (Judee K. Burgoon \& Saine, 1978), selfpresentation is the regulation of behavior for the purpose of creating an impression on others (Jones \& Pittman, 1982). All people are concerned with how they present themselves regardless of truth (e.g., competent, intelligent, kind), but deception can be considered a type of self-presentation where liars regulate their behaviors to falsely present themselves to others. DePaulo (1992) and Miller and Stiff (1993) applied this perspective to deceptive communication, contending that liars first form an intention to lie and regulate their nonverbal behavior - making their subsequent behaviors conscious and deliberate. Next, liars must translate their intentions to actual nonverbal behaviors meant to present themselves as truthful or honest. Liars may lack the ability, motivation, emotion, confidence, or ability to recreate spontaneous expressiveness or manage the behavior consciously. From this perspective, liars are predicted to unconvincingly embrace their self-presentations and to exhibit unnatural deliberateness in their actions (DePaulo et al., 2003). Based on these predictions, liars should appear more tense and less pleasant or compelling than someone speaking sincerely. Nonverbal indicators of these states include forced smiles, increased vocal pitch, rigid motions, and lack of engagement or holding back movements. 
DePaulo and Kirkendol (1989) introduced the moderating influence of motivation on deceptive nonverbal behavior. They predicted that an increase in motivation will cause a redoubling of selfregulation, already inherent in self-presentation, that inhibits nonverbal behavior and increases leakage cues (DePaulo et al., 2003). Burgoon and Floyd (2000) found that motivation can actually improve both verbal and nonverbal behavior irrespective of deception. Motivation is an important moderator of deceptive behavior, but there are individual and situational differences in how it impacts verbal and nonverbal behavior.

\subsection{Interpersonal Deception Theory}

To account for the complex interplay between liars and the deceived, Buller and Burgoon (1996) introduced interpersonal deception theory (IDT). This theory expanded and conceptualized deception as a strategic interaction between a sender and receiver, rather than focusing on just the liar during deceptive communication. Liars must simultaneously manage information, their behavior, and appearance during the interaction. Moreover, liars will use different strategies depending on their skill, relationship with the interaction partner, preparation, motivation, and time.

Liars are predicted to act both strategically (purposeful) and nonstrategically (involuntarily) in response to the interaction. An important element of IDT is the dynamics of behavior over the course of the interaction (time). Deceivers' behavior early in the interaction likely will be different later in response, both strategically and nonstrategically, to the feedback from their speaking partner. For example, deceivers might attempt to reduce the quality and quantity of message details to obfuscate what they are saying. If liars sense they have aroused suspicion in their speaking partner, they might shift strategies to increase their believability. Because deceivers are vigilant, cognitively taxed, and focused on their own behavior, nonstrategic behaviors (e.g., leakage cues) are predicted to be exhibited, but IDT predicts deceivers will make efforts to repair these performance impairments so that over time, their verbal and nonverbal behavior comes to resemble that of truth tellers. 


\section{Deception Detection by Humans}

People, whether unaided or trained, detect deception at near chance levels. A meta-analysis of over 206 deception studies that required participants to judge the honesty of liars or truth tellers (Bond \& DePaulo, 2006) showed that on average, judges of liars during deception experiments, performed slightly above chance with $54 \%$ accuracy in detection overall; they classified $47 \%$ of lies as deceptive and $61 \%$ of truths as truthful. Unless vigilant or suspicious, people maintain a truth bias and accept the truth of what they hear (i.e., deceivers go undetected). The converse is also true, a lie bias is often observed in law enforcement where the assumption is deception (i.e., truthful individuals are falsely accused). Regardless of lie or truth bias, overall accuracy of detection still remains at near chance. It is argued that one reason for detection inaccuracy is that people rely on stereotypical and incorrect indicators of deception such as lack of eye contact or fidgeting when judging honesty (Hartwig \& Bond, 2011; The Global Deception Research Team, 2006; A Vrij, Davies, \& Bull, 2008). Hartwig and Bond (2011) conducted a metaanalysis that found judges, despite their overall inaccuracy, perceived deception indicators accurately. Hartwig and Bond argue that deception detection judges have an implicit sensitivity to reliable deception cues. Only when asked to explicitly describe their decision criteria do people fall back on stereotypical cues of deception to explain their decisions.

Another reason offered for inaccuracy is that deceptive behavioral cues may not occur often or strongly enough to be noticed during interactions (DePaulo et al., 2003; Hartwig \& Bond, 2011). This is further complicated when considering IDT's prediction that behaviors indicating deception change over the course of the interaction and in response to the situational demands. Thus, deception indicators are ephemeral and replaced by behaviors that evoke credibility.

Regardless of the reason, people may profit from technological aids in identifying the correct behavioral cues and detecting deception. Notwithstanding this ever-present need, technologies for detecting deception that are available to law enforcement or border guards are very limited. The 
polygraph examination, which was primarily developed between 1895 and 1945 (Inbau, 1948; Reid, 1947; Skolnick, 1960) remains the most widespread deception detection technology.

Because the polygraph requires attaching multiple physiological instruments (blood pressure cuff, respiratory rate pneumograph, and galvanic skin resistance galvanometer) to the interviewee, because the protocol for administering the polygraph examination requires a lengthy (3-5 hours), multiphase interview to obtain reliability, and because these interviews are often preceded by background investigations that provide polygraph examiners additional information used to interpret and guide interviewing, the polygraph is unsuitable for rapid screening environments such as the airport or border that require unobtrusive and automated deception detection technology. Consequently, other tools must be developed, preferably ones that are theoretically driven and can detect the same classes of indicators that reliably discriminate truthful from deceptive communication. The next section reviews the causal mechanisms that are theorized to produce reliable indicators of truth or deception.

\section{Causal Mechanisms}

The various theories of deception indicators and deception point to an array of strategic and nonstrategic behaviors that are both valid and reliable discriminators of truth from deception. In order to develop algorithms and technology to detect and classify deception, these behaviors and physiology must be measured remotely. The theorized causes of observable behavior include the four factors from the leakage and four-factor theories plus memory effects. Each of these five causal factors is reviewed in turn.

\subsection{Arousal}

The most commonly associated class of indicators of deceit is arousal. Engaging in deceit is theorized to be distressing, causing liars to experience increased arousal such that the sympathetic nervous system excites the body in response to an imminent fight-or-flight event or potential threat monitoring invoked by the security motivation system (Woody \& Szechtman, 2011). It is these 
cardiorespiratory and galvanic skin physiological responses that are captured by the polygraph and are the impetus for most of the commercial products that have been billed as lie detection systems.

Previous research has revealed that liars often do exhibit one of two types of response patterns: either a generalized activation response or greater tension. Negatively valenced arousal can be revealed through greater pupil dilation or instability, postural shifting, fidgeting, random trunk and limb movements, hand adaptor gestures such as touching the face, neck or head with the hand, or lip adaptors such as biting, licking or puckering the lips. Tension, on the other hand, can manifest itself through frozen and rigid postures, lack of gestures or a tightening of the muscles in the vocal folds, which causes them to vibrate faster and produce a higher pitch (fundamental frequency) when speaking (Titze \& Martin, 1998).

Although arousal is the most commonly acknowledged overt manifestation of deceit, it should be noted that the relationship between deception and arousal is not deterministic. First, deceit does not inevitably trigger arousal. White lies, lies told for the benefit of the target, lies that are sanctioned by a given culture or community, lies that are sanctioned by an experimenter or authority, omissions, exaggerations and evasions, and the like may not cause the perpetrator of deceit to experience physiological changes. Second, internal experiences do not necessarily translate into external observable cues. People are capable of masking, minimizing, and replacing distress and arousal signals with outward displays that are socially appropriate and do not reveal the true internal state (P. Ekman, 1992; Fridlund, 1991). Third, a variety of factors other than deceit can cause arousal. Truth tellers, for example, may show signs of arousal if accused of wrongdoing or if questioned by authority. People may blush because they are embarrassed, even though they are not being deceptive. If both liars and truth tellers exhibit signs of arousal, then such signs cannot be used to identify truth. Fourth, different people may exhibit arousal in different ways. For example, one person may swivel in a chair, whereas the next person may "freeze" into a fixed posture with virtually no movement. Put differently, arousal can take many, substitutable forms (Judee K. Burgoon, Kelley, Newton, \& Keeley-Dyreson, 1989). Finally, the indicators of arousal may be feeble and transitory (DePaulo et al., 2003; Hartwig \& Bond, 2011), eluding detection because humans or instrumentation lack the sensitivity to capture them or because detection efforts are ill-timed (Hamel, 
Burgoon, Humpherys, \& Moffitt, 2007). For all these reasons, there is a lack of one-to-one correspondence between truth and arousal indicators, which undermines the diagnostic value of such indicators.

\subsection{Affect}

Ekman and Friesen (1969) initially posited that deceivers might show positive or negative emotions, negative emotions if they feared being detected or felt guilt about lying, positive emotions if they experienced "duping delight," that is enjoyment at having fooled others. However, writings about deception have most often claimed that deceivers will experience and express negative affect such as guilt or fear.

Nonverbally, in addition to expectations that such emotions will be displayed through the face in either full-fledged emotional displays or in fleeting micro-expressions (P. Ekman, 2003), some research has suggested that positive emotion is evident through felt smiles, as compared to feigned (Paul Ekman, Davidson, Friesen, \& others, 1990). The voice is also posited to convey positive or negative affect both in the form of specific emotional states and in general degrees of pleasantness or unpleasantness. Fearful people often speak louder and at faster tempo (P. N. Juslin \& Laukka, 2003; P. Juslin \& Scherer, 2005). In addition to nonverbal displays, affective states may be revealed through verbal content and linguistic style. For example, the words "love" or "nice" connote more positive emotion than "hurt" or "ugly" when used in speech or text (Francis \& Pennebaker, 1993; M. L. Newman, Pennebaker, Berry, \& Richards, 2003; Tausczik \& Pennebaker, 2010). Although deceivers have been postulated to use more affectively negative language than truth tellers, some results have shown them to use more affective language — both positive and negative — than truth tellers but only under certain circumstances (J. K. Burgoon, Hamel, \& Qin, 2012; Judee K. Burgoon \& Qin, 2006). 


\subsection{Cognitive Effort}

Because of self-regulation and increased strategic interaction requirements, deception is predicted to be more cognitively demanding then telling the truth (Buller \& Burgoon, 1996; DePaulo et al., 2003), a prediction borne out by a substantial meta-analysis by Sporer \& Schwandt (2006) who found that when liars lack preparation or rehearsal their enhanced taxation on working memory increases cognitive effort cues. When cognitively taxed, people often speak with more nonfluencies (e..g, "um”, "uh”, speech errors), take longer to respond to questions, cease gesturing, and avert their gaze. Eyeblinks occur spontaneously every few seconds, but only a fraction of these blinks are required for ocular lubrication. Eyeblinks signal disengagement from external stimulus (e.g., no longer watching speaking partner) to reallocate mental resources to facilitate cognitive behavior (Irwin \& Thomas, 2010; Nakano, Kato, Morito, Itoi, \& Kitazawa, 2012) Increased duration before the onset of an eyeblink indicates attention to external stimulus and minimization of visual information loss (Fukuda, 2001; Shultz, Klin, \& Jones, 2011).

\subsection{Behavioral Control}

Deception is often associated with a lack of movement. Deceivers, in an effort to control telltale signs of their deceit, may overcompensate by unnaturally over controlling their behaviors. Their overcontrol can result in wooden postures, inexpressive faces and gestures, and elevated vocal pitch. However, if such control is not extreme, it can instead appear as a composed, poised demeanor (J. Burgoon \& Floyd, 2000; Twyman, Elkins, \& Burgoon, 2011). Thus, efforts to measure tension and postural rigidity may require identifying a threshold beyond which the level of inactivity becomes unnatural. 


\subsection{Memory}

The role of memory in deceptive communication concerns the ability to access real versus imagined memories and the taxation that deceit imposes upon working memory. In their revision of the original four-factor theory and Vrij's (1999) perspective on cognitive effort, Sporer and Schwandt (2007) recast cognitive effort behavioral changes as being caused by accessing working memory. In the case of complex lies coming up with plausible stories and alibis taxes working memory. Not only must liars simultaneously plan what they are saying and avoid contradicting themselves or on facts known to the listener, they must also observe the listener's reactions, monitor their own behavior, and control their behavior. These multiple demands result in liars appearing to think hard, and to do such things as look away or delay responding while constructing answers, behaviors which may give them away (Mann, Vrij, \& Bull, 2002).

\section{Computational Modeling and Classifying Deception}

Based on deception theory and the predicted causes for verbal, nonverbal, and physiological behavior differences between liars and truth tellers, computational models can be developed for detecting deception. This section details current sensor based methods for automatically classifying

\subsection{Polygraph}

One of the first methods for automatic extraction of deception related cues is the polygraph. The polygraph monitors uncontrolled changes in heart rate, blood pressure, respiration, and electro-dermal response, as a result of the subject's elevated arousal when being deceptive. Contact sensors are placed on the subjects during examinations. The resulting signals are then heuristically analyzed by experts (BenShakhar \& Bar-Hillel, 1986; Elaad, 1998; Honts, Raskin, \& Kircher, 1987; Kleinmuntz \& Szucko, 1984; Saxe, Dougherty, \& Cross, 1985; Stern, 2002; Yankee, 1965). 
The polygraph exam process comes with various disadvantages. The comfort of subjects is affected by the attached sensors and can influence physiological measurements (Yankee, 1965). The person examined must be cooperative and in close proximity to the device. The analysis of the polygraph performed manually, based the subjective perceptions of the examiner and the scoring of the exam.

Despite the existence of automated scoring systems built into modern polygraph systems, most examiners base their decision on their own scoring of the exam.

Having conducted a set of laboratory tests, Vrij et al. (2008) suggested that the polygraph is about $82 \%$ accurate at identifying deceivers. The National Academy of Sciences (Stern, 2002), concluded that such experimental numbers are often overestimates of actual results. They argue laboratory examinations are conducted with complete control over threats to internal validity, unrepresentative subjects, unrealistic and uniform ground truth, and experimental polygraph exams occurs immediately after the investigated issue, which is uncommon in the real-world.

\subsection{Vocalics}

Vocalics is a family of techniques that analyze the voice during deceptive speech to measure changes in arousal and cognition (Cestaro \& Dollins, 1994; Cestaro, 1995; Janniro \& Cestaro, 1996). Vocal Stress Analysis (VSA) is a commercial application of vocalics marketed to law enforcement for deception detection (Cestaro, 1995). Many independent tests on various VSA did not yield detection rates that are better than chance (Harnsberger \& Hollien, 2009). Recently, new attempts were made to reinitiate research and investigate the validity of vocal analysis for deception detection (Elkins, Burgoon, \& Nunamaker, 2012). Previous research on commercial vocal analysis software has focused on validating their built-in lie or truth classifications. Analyzing the commercial software's calculated vocal measurements rather than the lie or truth classification, revealed sensitivity to both deception and arousal during deception experiments (Elkins \& Burgoon, 2010; Elkins, 2010). While commercial vocal analysis software is beginning to yield promising results for deception detection in the field, its contribution to research is limited because of the software's proprietary nature and ambiguously calculated vocal 
measurements. For example, the LVA 6.50 (Nemesysco, 2009) contains variables simply named SOS and AVJ that are documented to measure fear and thinking level respectively. While these variables have demonstrated sensitivity to experimentally induced deception, the results may support the validity of the software, but contribute little to our understanding of deceptive vocal behavior.

Research using standard acoustic measures, using freely available software tools such as Praat (Boersma, 2002) or openSMILE (Eyben, Wöllmer, \& Schuller, 2010), has found that liars speak with greater and more varied vocal pitch (Apple, Streeter, \& Krauss, 1979; DePaulo et al., 2003; Zuckerman et al., 1981), with shorter durations (Rockwell, Buller, \& Burgoon, 1997; A Vrij, Mann, et al., 2008), less fluency, and respond with greater response latencies (DePaulo, Stone, \& Lassiter, 1985; deTurck \& Miller, 2006; Rockwell et al., 1997; S. L. Sporer \& Schwandt, 2006).

\subsection{Linguistics}

Considerable research has been conducted to develop automatic linguistic analysis of text for extracting deceptive cues (Judee K. Burgoon, Blair, Tiantian, \& Nunamaker, 2003; Fuller \& Biros, 2013; Hancock, Curry, Goorha, \& Woodworth, 2004; M. Newman, Pennebaker, Berry, \& Richards, 2003; Toma \& Hancock, 2012; Zhou et al., 2003). There are many different lines of research. The main two revolve around synchronous communication (Judee K. Burgoon et al., 2003; Hancock et al., 2004; M. Newman et al., 2003; Toma \& Hancock, 2012), where the lie has to be made on the spot, (for example during interviews or online chat), and asynchronous scenarios (Fuller \& Biros, 2013; Zhou et al., 2003), where the lie can be carefully prepared beforehand (for example a deceitful court statement).

In a constant topic setting (M. Newman et al., 2003) in comparison to truth-tellers, liars' responses demonstrated lower cognitive complexity (more concrete verbs and less evaluative and judgment language), used fewer self-references and used more negative emotion words. In dyadic communication (Hancock et al., 2004) liars used more words overall, increased references to others, and used more sense-based descriptions (e.g., seeing, touching). Burgoon et al. investigated linguistic deception during a mock theft scenario (2003) where an interview was conducted using face-to-face, text 
chat, or audio conferencing. Deceivers' messages were briefer (i.e., lower on quantity of language), less complex in their choice of vocabulary and sentence structure, and lacked specificity or expressiveness in their text-based chats.

In asynchronous scenarios (Zhou et al., 2003) detailed lies can be produced with many complexities. This is more evident in high stakes asynchronous deception. Zhou and Zhang surveyed cues for each of these scenarios (2008).

Using automated text analysis and validated emotion dictionaries, previous research has revealed 21 linguistic cues and their corresponding categories that discriminate between deceptive verbal messages (M. L. Newman et al., 2003; Zhou et al., 2003; Zhou, Burgoon, Nunamaker, \& Twitchell, 2004). Linguistic cues can be extracted from deceptive verbal messages using automated linguistic analysis software such as Structured Programming for Linguistic Cue Extraction (SPLICE) (Moffitt, 2010), which incorporates the Dictionary of Affect in Language (DAL) (Whissell, 1989), and the Linguistic Inquiry and Word Count (LIWC) (Francis \& Pennebaker, 1993).

\subsection{Oculesics}

Eye behavior and blinks can be very useful cues in deceit detection (Bhaskaran, 2011; Fukuda, 2001; Minkov, Zafeiriou, \& Pantic, 2012; Nwogua, Frank, \& Govindaraju, 2010). Bhaskaran (2011) proposed an online person-specific learning approach for learning the typical eye behavior in baseline questions (no deception) and this model was later tested on the critical questions (deception) in order to spot differences (i.e., deceitful behavior). Eye blink dynamics, such as blink duration and rate (frequency), were used as cues for spotting deceit in the controversial TV show Moment of truth (Minkov et al., 2012). Pupil characteristics, such as pupil dilations, are cues of arousal or stress. Deception impacts pupillary response and leads to pupil dilation (Dionisio, Granholm, Hillix, \& Perrine, 2001; Lubow \& Fein, 1996).

When presented with visual stimulus, deceivers possessing guilty knowledge fixate on lie relevant images and increase their pupil dilation. Elkins, Derrick, and Gariup (2012) conducted an 
experiment where some participants lied about their identity (imposters) and presented a legitimate visa document during a simulated border screening. During the screening interview, participants were shown their own documents. Liars fixated on the incorrect fields (e.g., date of birth) of their document two times longer than truth tellers. Research investigating cognitively induced eye gaze activity (e.g., looking left when lying) has been limited and based only on the unsupported predictions from Neuro-Linguistic Programming (Wiseman et al., 2012).

\subsection{Body Posture, gesture and kinesics}

Multiple methods have been proposed for deriving indicators of deception from body posture (Judee K. Burgoon et al., 2009; Lu, Tsechpenakis, Metaxas, Jensen, \& Kruse, 2005; Meservy et al., 2005; Meservy, Jensen, Kruse, Burgoon, \& Nunamaker, 2008). These methods focus on deriving cues by tracking the location of the head and hands (Judee K. Burgoon et al., 2009; Lu et al., 2005; Meservy et al., 2005, 2008). Gesture analysis, posture and kinesics based features were extracted from the video using a method called "blob analysis" (i.e., head and hands were represented as blobs). The blobs of the head and hands were tracked and segmented from the video. Features include average and variance of the head position and angle, the average and variance of the positions of the head and hands, the average distance between the hands. Burgoon et al. (2009) developed behavioral profiles automatically detecting agitation (e.g., frequent face touching and hand to hand touching), over controlled (e.g., infrequent gesturing and rigid movement), and relaxed behavior (neither over controlled nor agitated) from video. These observed behavioral states taken in the context of an interaction can be caused by deception.

\subsection{Facial Behavior}

Current work in facial expression based deception detection seeks to identify either insincere emotional expressions (e.g., fake smiles) or leaked true expressions of emotion (Hurley \& Frank, 2011; Porter, Brinke, Baker, \& Wallace, 2011), that taken in context contradict a truthful person's expected 
emotion. In addition to emotion, facial expressions can also provide indicators of deception induced behavioral control (Michael, Dilsizian, Metaxas, \& Burgoon, 2010) .

Current work in automated facial expression recognition involves first identifying the face from each frame of a video (Viola \& Jones, 2004) and applying facial point tracking methods such as Active Shape Modeling (ASM) (Cootes, Taylor, Cooper, \& Graham, 1995) or Active Appearance Modeling (AAM) (Cootes, Edwards, \& Taylor, 2001; Tzimiropoulos, Alabort-i-medina, Zafeiriou, \& Pantic, 2012). Once facial points are tracked, methods can be applied to detect expressions from the temporal dynamics and activation of facial muscle action units (Pantic \& Patras, 2006; Valstar \& Pantic, 2006).

\subsection{Cardiorespiratory}

Pulse rate, blood pressure and respiration rate could be reliable indicators of emotional stress. There are claims that emotional stress varies between truth tellers and liars (Cutrow, Parks, Lucas, \& Thomas, 1972; Kurohara, Terai, Takeuchi, \& Umezawa, 2001). This is believed to result from an increase in cognitive effort and behavioral control needed to appear convincing. Differences in cardiovascular measures such as increased pulse rate have been identified during deceptive communication (Cutrow et al., 1972). Furthermore, studies have shown that individuals tend to inhibit breathing when faced with the kind of stress commonly found during deceptive situations (Kurohara et al., 2001). An additional advantage is that cardiorespiratory measurements can be collected in a noncontact manner using a Laser Doppler Vibrometer (LDV). The LDV uses a laser to measure carotid artery pulsations on the neck, which are processed to calculate cardiorespiratory measurements such as heart rate and blood pressure.

\subsection{Fusion}

Derrick et al. conducted a study on deception detection using a mock crime experimental paradigm that included the fusion of multiple behavioral sensors (Derrick, Elkins, Burgoon, Nunamaker Jr, \& Zeng, 2010). Derrick et al. found that deceivers increased their heart rate (measured using LDV) in 
anticipation to lie relevant stimulus and then decreased their heart rate after experiencing the stimulus. Building a deception classifier using LDV alone resulted in a $77 \%$ true positive rate, but a $42 \%$ false positive rate. Human judges of deception during the same experiment had an accuracy of $71.2 \%$ overall. When the LDV and human judgments were fused into a single classification, the true positive rate increased to $90 \%$, with only a $2.8 \%$ increase in false positives.

Fusion pools multiple sensors to increase the reliability and validity of deception judgments by measuring multiple causal mechanisms and behavioral modalities. This improves detection accuracy because there is high variance between people on the behaviors they express when lying. For some people, their voice is strongly affected (e.g., increased vocal pitch) and others my increase their postural rigidity. While everyone has varying degrees of ability to control some behaviors, they cannot control them all; fusion decreases the likelihood of missing important behavioral cues and improves reliability and convergent validity.

\section{Current Applications of Deception Detection}

\subsection{Border Control and Automated Screening}

One major challenge to deception detection is accounting for the variability introduced by human interviewers. Every interviewer has their own style (e.g., aggressive, friendly), inconsistently asks questions, and gets tired. The behavior and approach of the interviewer strongly influences the behavior and reactions of the interviewee. For example, if the interviewer is angry, the interviewee will be affected by this and artificially display reciprocal anger or even distress. Perhaps after a lunch break the interviewer is fresh and in better spirits and returns to a more friendly interaction. Any deception detection system that relies on consistent behavioral cues will have to account for the diverse range of human interviewer variability. 
To address this challenge, Nunamaker et al. (Elkins, Derrick, \& Gariup, 2012; Elkins \& Derrick, 2013; Elkins, Sun, Zafeiriou, \& Pantic, 2013; Nunamaker Jr. et al., 2011) developed an Embodied Conversational Agent (ECA) based deception detection system called AVATAR. AVATAR was developed to optimize internal validity by controlling question delivery, dynamically branching based on interrogation protocols such as Behavioral Analysis Interview (Horvath, Blair, \& Buckley, 2008), to improve the reliability of behavioral cue interpretation. The ECA system uses multiple integrated behavioral sensors (e.g., microphone, camera, eye tracker) to monitor verbal and nonverbal behavior during the interview. These sensors streams are fused and submitted to a robust classification engine that does not rely on any single indicator or modality of deceptive behavior (Elkins, Derrick, Burgoon, \& Nunamaker Jr, 2012).

Because the AVATAR is consistent in administering the interview (unlike human judges) it does not contribute additional variance into the deception classification. The ECA within the AVATAR can also take on any demeanor (e.g., friendly, stern) or embodiment (e.g., male, female) that will elicit the most diagnostic behavior. During the interview, the AVATAR conducts an interview protocol designed to exaggerate the differences in predicted behavior between liars and truth tellers. For example, Elkins, Derrick, and Gariup (2012) conducted an experiment where participants were interviewed in a mock screening scenario by the AVATAR. Some of the participants were assigned to the imposter group and lied to the AVATAR about their identity. Using the eye behavior and voice, the AVATAR was able to identify psueudo-imposters with over $94 \%$ accuracy. In contrast with traditional deception research, studies conducted with AVATAR are very specific and unique to the scenario deployed. There are no expectations that the eye behavior or voice exhibited by liars should generalize outside of the imposter context it has been tested in. 


\subsection{Other Applications}

While the initial applications for automated verbal and nonverbal behavior analysis are for deception detection, the underlying detection of emotion, cognition, arousal, and causal factors are relevant to many human-computer-interaction scenarios. For example, Elkins and Derrick (2012) propose the voice for the measurement of trust by new employees and team members to facilitate management and collaboration. Any scenario where one could benefit from real-time feedback of a speaking can could be a potential application — hospital patient triage and treatment, clinical therapy, insurance fraud detection, law enforcement interviewing, assisted communication for the disabled, and richer interactions and interfacing with computers.

\section{Future Research}

Future research should focus more on behavior over the entire interaction. While some of the deception predictions using behavioral measurements perform better than chance, there is still much unaccounted variability overall. Interpersonal deception theory (IDT) predicts that deceptive behavior is dynamic and varies as a function of sender, receiver, time, deception, suspicion, motivation, and social skills. However, most deception experiments and even the polygraph exam focus on behavior difference scores over a set of questions. It is clear that this design ignores all of the important contextual and temporal information, such as the interaction between the behavior of speaking partners (e.g., synchrony, mimicry). Additionally, most deception research to date has focused on individual indicators or modalities of deception. Just like when we appraise the behavior of a speaking partner, relying on the voice, facial expressions, body posture, or language, we will need to provide computers with at least as much information as we processes when evaluating or classifying deception. To accomplish this, future research must fuse and analyze multiple behavioral and physiological sensors when modeling emotion and deception. 


\section{References}

Apple, W., Streeter, L. a., \& Krauss, R. M. (1979). Effects of pitch and speech rate on personal attributions. Journal of Personality and Social Psychology, 37(5), 715-727. doi:10.1037/0022-3514.37.5.715

Ben-Shakhar, G., \& Bar-Hillel, M. (1986). Trial by polygraph: Scientific and juridical issues in lie detection. Behavioral Sciences \& the Law, 4(4), 459-479. Retrieved from http://onlinelibrary.wiley.com/doi/10.1002/bsl.2370040408/abstract

Bhaskaran, N. (2011). Lie to Me: Deceit detection via online behavioral learning. Automatic Face \& Gesture Recognition, 24-29. Retrieved from http://ieeexplore.ieee.org/xpls/abs_all.jsp?arnumber=5771407

Boersma, P. (2002). Praat, a system for doing phonetics by computer. Glot international, $5(9 / 10), 341-345$.

Bond, C. F., \& DePaulo, B. M. (2006). Accuracy of deception judgments. Personality and Social Psychology Review, 10(3), 214.

Buller, D. B., \& Burgoon, J. K. (1996). Interpersonal Deception Theory. Communication Theory, 6(3), 203-242. doi:10.1111/j.1468-2885.1996.tb00127.x

Burgoon, J., \& Floyd, K. (2000). Testing for the motivation impairment effect during deceptive and truthful interaction. Western Journal of Communication, 64(3), 243-267. Retrieved from http://www.tandfonline.com/doi/abs/10.1080/10570310009374675

Burgoon, J. K., Hamel, L., \& Qin, T. (2012). Predicting veracity from linguistic indicators. Workshop on Innovation in Border Control. Odense, Denmark.

Burgoon, Judee K., Blair, J., Tiantian, Q., \& Nunamaker, J. F. (2003). Detecting deception through linguistic analysis. Proceedings of the 1st NSF/NIJ conference on Intelligence and Security Informatics. Retrieved from http://link.springer.com/chapter/10.1007/3-540-44853$5 \_7$

Burgoon, Judee K., Kelley, D. L., Newton, D. A., \& Keeley-Dyreson, M. P. (1989). The nature of arousal and nonverbal indices. Human Communication Research, (16), 217-255.

Burgoon, Judee K., \& Qin, T. (2006). No The dynamic nature of deceptive verbal communication. Journal of Language and Social Psychology, 26, 76-96.

Burgoon, Judee K., \& Saine, T. J. (1978). The unspoken dialogue. Boston: Houghton-Mifflin.

Burgoon, Judee K., Twitchell, D. P., Jensen, M. L., Meservy, T. O., Adkins, M., Kruse, J., Deokar, A. V., et al. (2009). Detecting Concealment of Intent in Transportation Screening: 
A Proof of Concept. Intelligent Transportation Systems, IEEE Transactions on Intelligent Transportation Systems, 10(1), 103-112.

Cestaro, V. (1995). A Comparison Between Decision Accuracy Rates Obtained Using the Polygraph Instrument and the Computer Voice Stress Analyzer (CVSA) in the Absence of. Polygraph, 25(2), 117-127. Retrieved from http://oai.dtic.mil/oai/oai?verb=getRecord\&metadataPrefix=html\&identifier=ADA300334

Cestaro, V., \& Dollins, A. (1994). An Analysis of Voice Responses for the Detection of Deception. Polygraph, 25(1), 15-342. Retrieved from http://oai.dtic.mil/oai/oai?verb=getRecord\&metadataPrefix=html\&identifier=ADA298417

Cootes, T., Edwards, G., \& Taylor, C. (2001). Active appearance models. IEEE Transactions on Pattern Analysis and Machine Intelligence, 23(6), 681-685. Retrieved from http://ieeexplore.ieee.org/xpls/abs_all.jsp?arnumber $=927467$

Cootes, T., Taylor, C., Cooper, D., \& Graham, J. (1995). Active shape models-their training and application. Computer vision and image ..., 61(1), 38-59. Retrieved from http://www.sciencedirect.com/science/article/pii/S1077314285710041

Cutrow, R., Parks, A., Lucas, N., \& Thomas, K. (1972). The objective use of multiple physiological indices in the detection of deception. Psychophysiology. Retrieved from http://onlinelibrary.wiley.com/doi/10.1111/j.1469-8986.1972.tb00767.x/abstract

DePaulo, B. M. (1992). Nonverbal behavior and self-presentation. Psychological bulletin, 111(2), 203-43. Retrieved from http://www.ncbi.nlm.nih.gov/pubmed/1557474

DePaulo, B. M., \& Kirkendol, S. E. (1989). The motivational impairment effect in the communication of deception. In J. Yuille (Ed.), Credibility Assessment (p. 1996). Deurne, Belgium: Kluwer.

DePaulo, B. M., Lindsay, J. J., Malone, B. E., Muhlenbruck, L., Charlton, K., \& Cooper, H. (2003). Cues to deception. Psychological Bulletin, 129(1), 74-118. doi:10.1037/00332909.129.1.74

DePaulo, B. M., Stone, J. I., \& Lassiter, G. D. (1985). Deceiving and detecting deceit. The self and social life, 323.

Derrick, D. C., Elkins, A. C., Burgoon, J. K., Nunamaker Jr, J. F., \& Zeng, D. D. (2010). Border Security Credibility Assessments via Heterogeneous Sensor Fusion. IEEE Intelligent Systems, 25(May/June), 41-49. Retrieved from http://www.computer.org/portal/web/csdl/doi/10.1109/MIS.2010.79

deTurck, M., \& Miller, G. (2006). Deception and arousal. Human Communication Research, 12, 181-201. 
Dionisio, D., Granholm, E., Hillix, W. A., \& Perrine, W. F. (2001). Differentiation of deception using pupillary responses as an index of cognitive processing. Psychophysiology, 38(2), 205-211. Retrieved from http://onlinelibrary.wiley.com/doi/10.1111/14698986.3820205/full

Ekman, P, \& Friesen, W. V. (1969). Nonverbal leakage and clues to deception. Psychiatry, $32(1), 88-106$.

Ekman, P. (1992). Telling lies: Clues to deceit in the marketplace, politics, and marriage. New York: Norton.

Ekman, P. (2003). Darwin, deception and facial expression. Annals of the New York Academy of Sciences, (1000), 205-221.

Ekman, Paul, Davidson, R. J., Friesen, W. V, \& others. (1990). The Duchenne smile: Emotional expression and brain physiology II. Journal of personality and social psychology, 58(2), $342-353$.

Elaad, E. (1998). The challenge of the concealed knowledge polygraph test. Expert Evidence, 6 , 161-187. Retrieved from http://link.springer.com/article/10.1023/A:1008855511254

Elkins, A. C. (2010). Evaluating the Credibility Assessment Capability of Vocal Analysis Software. Forty-Third Annual Hawaii International Conference on System Sciences. Koloa, Kauai, Hawaii.

Elkins, A. C., \& Burgoon, J. K. (2010). Validating Vocal Analysis Software to Assess Credibility in Interpersonal Interaction: A Multilevel Factor Analytic Approach. National Communication Association 96th Annual Convention. San Francisco, California.

Elkins, A. C., Burgoon, J. K., \& Nunamaker, J. F. (2012). Vocal Analysis Software for Security Screening: Validity and Deception Detection Potential. Homeland Security Affairs.

Elkins, A. C., \& Derrick, D. C. (2013). The Sound of Trust: Voice as a Measurement of Trust During Interactions with Embodied Conversational Agents. Group Decision and Negotiation.

Elkins, A. C., Derrick, D. C., Burgoon, J. K., \& Nunamaker Jr, J. F. (2012). Predicting Users' Perceived Trust in Embodied Conversational Agents Using Vocal Dynamics. Forty-Fifth Annual Hawaii International Conference on System Sciences. Maui, Hawaii.

Elkins, A. C., Derrick, D. C., \& Gariup, M. (2012). The Voice and Eye Gaze Behavior of an Imposter: Automated Interviewing and Detection for Rapid Screening at the Border. Conference of the European Chapter of the Association for Computational Linguistics. Avignon, France. 
Elkins, A. C., Sun, Y., Zafeiriou, S., \& Pantic, M. (2013). The face of an imposter: Computer Vision for Deception Detection. Forty-Sixth Annual Hawaii International Conference on System Sciences. Maui, Hawaii.

Eyben, F., Wöllmer, M., \& Schuller, B. (2010). Opensmile: the munich versatile and fast opensource audio feature extractor (pp. 1459-1462). Retrieved from http://portal.acm.org/citation.cfm?id=1874246

Francis, M. E., \& Pennebaker, J. W. (1993). LIWC: Linguistic inquiry and word count. Dallas, Texas: Southern Methodist University.

Fridlund, A. J. (1991). Evolution and facial action in reflex, social motive, and paralanguage. Biological Psychology, (32), 3-100.

Fukuda, K. (2001). Eye blinks: new indices for the detection of deception. International Journal of Psychophysiology, 40(3), 239-245. Retrieved from http://www.sciencedirect.com/science/article/B6T3M-42DP0HD9/2/42558dccec4cd2e4c1c959566fc35c41

Fuller, C., \& Biros, D. (2013). An examination and validation of linguistic constructs for studying high-stakes deception. Group Decision and Negotiation, 1-18. Retrieved from http://link.springer.com/article/10.1007/s10726-012-9300-z

Hamel, L., Burgoon, J. K., Humpherys, S., \& Moffitt, K. (2007). The "when" of deception detection. National Communication Association. Chicago, IL.

Hancock, J. T., Curry, L. E., Goorha, S., \& Woodworth, M. T. (2004). Lies in conversation: An examination of deception using automated linguistic analysis. Annual Conference of the Cognitive Science Society (Vol. 26, pp. 534-540). An examination of deception using automated linguistic analysis.

Harnsberger, J., \& Hollien, H. (2009). Stress and Deception in Speech: Evaluating Layered Voice Analysis. Journal of Forensic Sciences, 54(3), 642-50. doi:10.1111/j.15564029.2009.01026.x

Hartwig, M., \& Bond, C. F. (2011). Why do lie-catchers fail? A lens model meta-analysis of human lie judgments. Psychological bulletin, 137(4), 643-59. doi:10.1037/a0023589

Honts, C. R., Raskin, D. C., \& Kircher, J. C. (1987). Effects of physical countermeasures and their electromyographic detection during polygraph tests for deception. Journal of Psychophysiology, 1, 241-247.

Horvath, F., Blair, J., \& Buckley, J. P. (2008). The behavioural analysis interview: clarifying the practice, theory and understanding of its use and effectiveness. International Journal of Police Science and Management, 10(1), 101-118. doi:10.1350/ijpsm.2008.10.1.68 
Hurley, C. M., \& Frank, M. G. (2011). Executing Facial Control During Deception Situations. Journal of Nonverbal Behavior, 1-13. doi:10.1007/s10919-010-0102-1

Inbau, F. E. (1948). Lie detection and criminal interrogation. Williams \& Wilkins Co.

Irwin, D. E., \& Thomas, L. E. (2010). Eyeblinks and Cognition. Tutorials in Visual Cognition (pp. 121-141).

Janniro, M., \& Cestaro, V. (1996). Effectiveness of Detection of Deception Examinations Using the Computer Voice Stress Analyzer., 28-34. Retrieved from http://oai.dtic.mil/oai/oai?verb=getRecord\&metadataPrefix=html\&identifier=ADA318986

Jones, E., \& Pittman, T. S. (1982). Toward a general theory of strategic self-presentation. In J. Suls (Ed.), Psychological perspectives on the self (pp. 231-262). Hillsdale, NJ: Erlbaum.

Juslin, P. N., \& Laukka, P. (2003). Communication of emotions in vocal expression and music performance: Different channels, same code? Psychological Bulletin, 129(5), 770-814.

Juslin, P., \& Scherer, K. R. (2005). Vocal expression of affect. The new handbook of methods in nonverbal behavior research (pp. 65-135). Oxford University Press, USA. Retrieved from http://scholar.google.com/scholar?hl=en\&btnG=Search\&q=intitle:Vocal+expression+of+aff ect\#0

Kleinmuntz, B., \& Szucko, J. (1984). Lie detection in ancient and modern times: A call for contemporary scientific study. The American Psychologist, 39(7), 766. Retrieved from http://cat.inist.fr/?aModele=afficheN\&cpsidt=8921762

Knapp, M. L., \& Comadena, M. E. (1979). Telling it like it isn't: A review of theory and research on deceptive communications. Human Communication Research, 5(3), 270-285.

Kurohara, A., Terai, K., Takeuchi, H., \& Umezawa, A. (2001). Respiratory changes during detection of deception: Mechanisms underlying inhibitory breathing in response to critical questions. Japanese Journal of Physiological Psychology and Psychophysiology, 19(2), 7585. Retrieved from http://sciencelinks.jp/j-east/article/200205/000020020501A1025296.php

Lu, S., Tsechpenakis, G., Metaxas, D., Jensen, M., \& Kruse, J. (2005). Blob analysis of the head and hands: A method for deception detection. Thirty-Eighth Annual Hawaii International Conference on System Sciences. Retrieved from http://ieeexplore.ieee.org/xpls/abs_all.jsp?arnumber=1385269

Lubow, R., \& Fein, O. (1996). Pupillary size in response to a visual guilty knowledge test: New technique for the detection of deception. Journal of Experimental Psychology: Applied, 2(2), 164-177. Retrieved from http://psycnet.apa.org/?fa=main.doiLanding\&doi=10.1037/1076-898X.2.2.164 
Mann, S., Vrij, A., \& Bull, R. (2002). Suspects, Lies, and Videotape: An Analysis of Authentic High-Stake Liars. Law and Human Behavior, 26(3), 365-376.

McCornack, S. (1992). Information manipulation theory. Communications Monographs, 59(March). Retrieved from

http://www.tandfonline.com/doi/abs/10.1080/03637759209376245

Meservy, T., Jensen, M., Burgoon, J. K., Nunamaker, J. F., Twitchell, D. P., Tsechpenakis, G., \& Metaxas, D. (2005). Deception detection through automatic, unobtrusive analysis of nonverbal behavior. Intelligent Systems, IEEE, 20(5), 35-43. Retrieved from http://ieeexplore.ieee.org/xpls/abs_all.jsp?arnumber $=1511998$

Meservy, T., Jensen, M., Kruse, W., Burgoon, J. K., \& Nunamaker, J. F. (2008). Automatic extraction of deceptive behavioral cues from video. Terrorism Informatics. Retrieved from http://link.springer.com/chapter/10.1007/978-0-387-71613-8_23

Michael, N., Dilsizian, M., Metaxas, D., \& Burgoon, J. K. (2010). Motion profiles for deception detection using visual cues. Computer Vision-ECCV, 462-475. Retrieved from http://link.springer.com/chapter/10.1007/978-3-642-15567-3_34

Miller, G. R., \& Stiff, J. B. (1993). Deceptive communication. Thousand Oaks, CA: Sage.

Minkov, K., Zafeiriou, S., \& Pantic, M. (2012). A comparison of different features for automatic eye blinking detection with an application to analysis of deceptive behavior. Proceedings of the 5th International Symposium on Communications, Control and Signal Processing (pp. 1-4). Rome, Italy: Communications Control and Signal Processing ( $\{$ ISCCSP $\})$. Retrieved from http://ieeexplore.ieee.org/xpls/abs_all.jsp?arnumber=6217806

Moffitt, K. (2010). Structured Programming for Linguistic Cue Extraction. Retrieved from http://splice.cmi.arizona.edu

Nakano, T., Kato, M., Morito, Y., Itoi, S., \& Kitazawa, S. (2012). Blink-related momentary activation of the default mode network while viewing videos. Proceedings of the National Academy of Sciences, 3-7. doi:10.1073/pnas.1214804110

Nemesysco. (2009). Layered Voice Analysis (LVA) Technology White Paper Introduction. Netania, Israel. Retrieved from http://www.lva650.com/

Newman, M. L., Pennebaker, J. W., Berry, D. S., \& Richards, J. M. (2003). Lying words: Predicting deception from linguistic styles. Personality and Social Psychology Bulletin, 29(5), 665. doi:10.1177/0146167203251529

Newman, M., Pennebaker, J., Berry, D., \& Richards, J. (2003). Lying words: Predicting deception from linguistic styles. Personality and Social Psychology Bulletin, 29(5), 665675. Retrieved from http://psp.sagepub.com/content/29/5/665.short 
Nunamaker, J. F., Derrick, D. C., Elkins, A. C., Burgoon, J. K., \& Patton, M. (2011). A System Model for Human Interactions with Intelligent, Embodied Conversational Agents. Journal of Management Information Systems.

Nunamaker Jr., J. F., Derrick, D. C., Elkins, A. C., Burgoon, J. K., Patton, M. W., \& Nunamaker, J. F. (2011). Embodied Conversational Agent-Based Kiosk for Automated Interviewing. Journal of Management Information Systems, 28(1), 17-48. doi:10.2753/MIS07421222280102

Nwogua, I., Frank, M., \& Govindaraju, V. (2010). An automated process for deceit detection. Proceedings SPIE 7667, Biometric Technology for Human Identification VII (Vol. 7667). Retrieved from http://proceedings.spiedigitallibrary.org/data/Conferences/SPIEP/8052/76670R_1.pdf

Pantic, M., \& Patras, I. (2006). Dynamics of Facial Expression: Recognition of Facial Actions and Their Temporal Segments from Face Profile Image Sequences. IEEE Transactions on Systems, Man and Cybernetics - Part B, 36(2), 433-449.

Porter, S., Brinke, L., Baker, A., \& Wallace, B. (2011). Would I lie to you?"Leakage” in deceptive facial expressions relates to psychopathy and emotional intelligence. Personality and Individual ..., 2(51), 133-137. Retrieved from http://scholar.google.com/scholar?hl=en\&btnG=Search\&q=intitle:Would+I+lie+to+you?\#0

Reid, J. E. (1947). A revised questioning technique in lie-detection tests. Journal of Criminal Law and Criminology (1931-1951), 542-547. Retrieved from http://www.jstor.org/stable/1138979

Rockwell, P., Buller, D., \& Burgoon, J. (1997). The voice of deceit: Refining and expanding vocal cues to deception. Communication Research .... Retrieved from http://www.tandfonline.com/doi/full/10.1080/08824099709388688

Saxe, L., Dougherty, D., \& Cross, T. (1985). The validity of polygraph testing: Scientific analysis and public controversy. American Psychologist, 40, 355-366. Retrieved from http://www.ncjrs.gov/App/abstractdb/AbstractDBDetails.aspx?id=97661

Shultz, S., Klin, A., \& Jones, W. (2011). Inhibition of eye blinking reveals subjective perceptions of stimulus salience. Proceedings of the National Academy of Sciences of the United States of America, 108(52), 21270-5. doi:10.1073/pnas.1109304108

Skolnick, J. H. (1960). Scientific Theory and Scientific Evidence: An Analysis of Lie-Detection. The Yale Law Journal, 70, 694. Retrieved from http://heinonlinebackup.com/hol-cgibin/get_pdf.cgi?handle=hein.journals/ylr70\&section=53

Sporer, S. L., \& Schwandt, B. (2006). Paraverbal indicators of deception: a meta-analytic synthesis. Applied Cognitive Psychology, 20(4), 421-446. doi:10.1002/acp.1190 
Sporer, S., \& Schwandt, B. (2007). Moderators of nonverbal indicators of deception: A metaanalytic synthesis. Psychology, Public Policy, and Law, 13(1), 1-34. Retrieved from https://litigation-

essentials.lexisnexis.com/webcd/app?action=DocumentDisplay\&crawlid=1\&doctype=cite \& docid $=13+$ Psych. + Pub.+Pol.+and + L. $+1 \&$ srctype $=$ smi\&srcid=3B15\&key $=118 \mathrm{~b} 051 \mathrm{dc} 965 \mathrm{e} 4$ 9db51b1fd4db1de66c

Stern, P. (2002). The polygraph and lie detection: Report of the National Research Council Committee to review the scientific evidence on the polygraph.

Tausczik, Y. R., \& Pennebaker, J. W. (2010). The psychological meaning of words: LIWC and computerized text analysis methods. Journal of Language and Social Psychology, 29, 24.

The Global Deception Research Team. (2006). A World of Lies. Journal of Cross-Cultural Psychology, 37(1), 60-74. doi:10.1177/0022022105282295

Titze, I. R., \& Martin, D. W. (1998). Principles of voice production. Acoustical Society of America Journal, 104, 1148.

Toma, C., \& Hancock, J. (2012). What lies beneath: The linguistic traces of deception in online dating profiles. Journal of Communication, 62(1), 78-97. Retrieved from http://onlinelibrary.wiley.com/doi/10.1111/j.1460-2466.2011.01619.x/full

Twyman, N., Elkins, A. C., \& Burgoon, J. K. (2011). A Rigidity Detection System for the Guilty Knowledge Test. Forty-Fourth Annual Hawaii International Conference on System Sciences. Koloa, Kauai, Hawaii.

Tzimiropoulos, G., Alabort-i-medina, J., Zafeiriou, S., \& Pantic, M. (2012). Generic Active Appearance Models Revisited. 11th Asian Conference on Computer Vision (pp. 650-663).

Valstar, M., \& Pantic, M. (2006). Fully Automatic Facial Action Unit Detection and Temporal Analysis. Conference on Computer Vision and Pattern Recognition Workshop (p. 149). Ieee. doi:10.1109/CVPRW.2006.85

Viola, P., \& Jones, M. J. (2004). Robust real-time face detection. International Journal of Computer Vision, 57(2), 137-154.

Vrij, A, Davies, G., \& Bull, R. (2008). Detecting lies and deceit: Pitfalls and opportunities. West Sussux, England: Wiley-Interscience.

Vrij, A, Mann, S., Fisher, R., Leal, S., Milne, R., \& Bull, R. (2008). Increasing cognitive load to facilitate lie detection: The benefit of recalling an event in reverse order. Law and Human Behavior, 32, 253-265.

Vrij, Aldert, \& Heaven, S. (1999). Vocal and verbal indicators of deception as a function of lie complexity. Psychology, Crime \& Law, 5(3), 203-215. doi:10.1080/10683169908401767 
Whissell, C. M. (1989). The dictionary of affect in language. The measurement of emotion, 113131.

Wiseman, R., Watt, C., Ten Brinke, L., Porter, S., Couper, S.-L., \& Rankin, C. (2012). The eyes don't have it: lie detection and Neuro-Linguistic Programming. PloS one, 7(7), e40259. doi:10.1371/journal.pone.0040259

Woody, E. Z., \& Szechtman, H. (2011). Adaptation to potential threat: the evolution, neurobiology, and psychopathology of the security motivation system. Neuroscience and biobehavioral reviews, 35(4), 1019-33. doi:10.1016/j.neubiorev.2010.08.003

Yankee, W. (1965). An investigation of sphygmomanometer discomfort thresholds in polygraph examinations. Police, 9(6), 12.

Zhou, L., Burgoon, J. K., Nunamaker, J. F., \& Twitchell, D. (2004). Automating LinguisticsBased Cues for Detecting Deception in Text-Based Asynchronous Computer-Mediated Communications. Group Decision and Negotiation, 13(1), 81-106. doi:10.1023/B:GRUP.0000011944.62889.6f

Zhou, L., Twitchell, D. P. D. D. P. P., Qin, T., Burgoon, J. K., Nunamaker, J. F. F. J. F., Zhou, Tiantian Qin, et al. (2003). An exploratory study into deception detection in text-based computer-mediated communication. Thirty-Sixth Annual Hawaii International Conference on System Sciences (Vol. 51, p. 10). IEEE. Retrieved from http://ieeexplore.ieee.org/xpls/abs_all.jsp?arnumber=1173793

Zhou, L., \& Zhang, D. (2008). Following linguistic footprints: automatic deception detection in online communication. Communications of the ACM. Retrieved from http://dl.acm.org/citation.cfm?id=1389972

Zuckerman, M., DePaulo, B. M., \& Rosenthal, R. (1981). Verbal and Nonverbal Communication of Deception. Advances in Experimental Social Psychology (pp. 1-59). New York: NY: Academic Press. 